Jay H. Bernstein —Kingsborough Community College

\title{
The Data-Information-Knowledge-Wisdom Hierarchy and its Antithesis
}

\begin{abstract}
The now taken-for-granted notion that data lead to information, which leads to knowledge, which in turn leads to wisdom was first specified in detail by R. L. Ackoff in 1988. The Data-Information-KnowledgeWisdom hierarchy is based on filtration, reduction, and transformation. Besides being causal and hierarchical, the scheme is pyramidal, in that data are plentiful while wisdom is almost nonexistent. Ackoff's formula linking these terms together this way permits us to ask what the opposite of knowledge is and whether analogous principles of hierarchy, process, and pyramiding apply to it. The inversion of the DataInformation-Knowledge-Wisdom hierarchy produces a series of opposing terms (including misinformation, error, ignorance, and stupidity) but not exactly a chain or a pyramid. Examining the connections between these phenomena contributes to our understanding of the contours and limits of knowledge.
\end{abstract}

This presentation will revisit the Data-Information-Knowledge-Wisdom hierarchy linking these concepts together as stages of a single developmental process, with the aim of building a taxonomy for a postulated opposite of knowledge, which I will call 'nonknowledge'.

Concepts of data, information, knowledge, and wisdom are the building blocks of library and information science. Discussions and definitions of these terms pervade the literature from introductory textbooks to theoretical research articles (see Zins, 2007). Expressions linking some of these concepts predate the development of information science as a field of study (Sharma 2008). But the first to put all the terms into a single formula was Russell Lincoln Ackoff, in 1989.

Ackoff posited a hierarchy at the top of which lay wisdom, and below that understanding, knowledge, information, and data, in that order. Furthermore, he wrote that "each of these includes the categories that fall below it," and estimated that "on average about forty percent of the human mind consists of data, thirty percent information, twenty percent knowledge, ten percent understanding, and virtually no wisdom" (Ackoff, 1989, 3). This phraseology allows us to view his model as a pyramid, and indeed it has been likened to one ever since (Rowley, 2007; see figure 1). ('Understanding' is omitted, since subsequent formulations have not picked up on it.)

Ackoff was a management consultant and former professor of management science at the Wharton School specializing in operations research and organizational theory. His article formulating what is now commonly called the Data-InformationKnowledge-Wisdom hierarchy (or DIKW for short) was first given in 1988 as a presidential address to the International Society for General Systems Research. This background may help explain his approach. Data in his terms are the product of observations, and are of no value until they are processed into a usable form to become information. Information is contained in answers to questions. Knowledge, the next layer, further refines information by making "possible the transformation of information into instructions. It makes control of a system possible" (Ackoff, 1989, 4), and that enables one to make it work efficiently. A managerial rather than scholarly perspective runs through Ackoff's entire hierarchy, so that "understanding" for him 
connotes an ability to assess and correct for errors, while "wisdom" means an ability to see the long-term consequences of any act and evaluate them relative to the ideal of total control (omnicompetence). While a scholarly perspective on this hierarchy might prioritize the processes of inquiry and discovery, Ackoff does not account for them. But his concept of omnicompetence, which refers to "the ability to satisfy any and every desire" (Ackoff, 1989, 8), does encompass the satisfaction of user-defined needs.

Figure 1. The Data-Information-Knowledge-Wisdom hierarchy as a pyramid

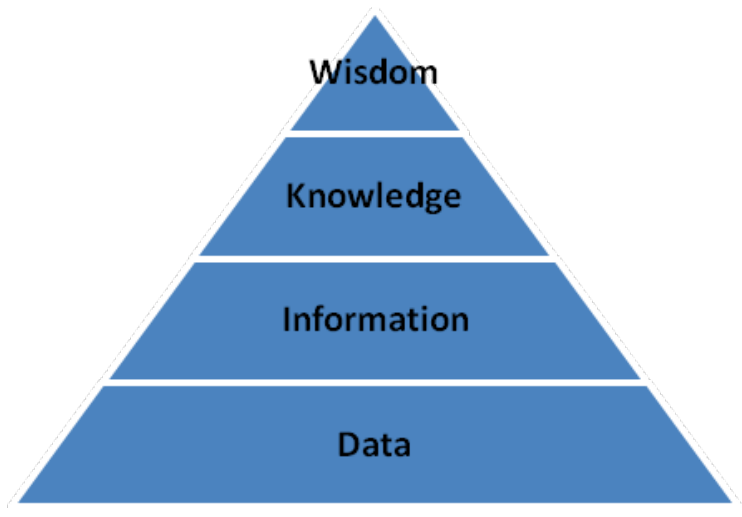

In creating his hierarchy, Ackoff focused only on specific modes of data, information, knowledge, and wisdom, and neglected important distinctions observed by information scientists such as Buckland (1991), Machlup (1980), and Soergel (1985). Clearly his model was directed primarily to the management of organizations and only incidentally, if at all, to bibliographic materials and collections. But the notion of interconnecting these phenomena as processes leading from raw data to wisdom through filtration, reduction, and refinement created a powerful image of great value in library and information science instruction and reflection for further research, shedding light on the very nature of knowledge. In designing and managing systems to organize information resources for retrieval we would like to know how data are transformed into more complex phenomena. The hierarchy can also be used in reverse to see how an example of wisdom was derived from phenomena at a lower level. With managerial astuteness, Ackoff understood progression through the hierarchy to proceed on the basis of increasing control. Crucially, Ackoff did not end his schema with knowledge but went further to tie the entire system together with wisdom, an ideal state, at the pinnacle.

Despite objections that the model glosses over the various different kinds of data, information, knowledge, and wisdom, this hierarchical and pyramidal model captures certain insights useful not only to personnel and organizational management but to the organization of library resources. By providing a model of the ontology and structure of knowledge it has become canonical to the field of knowledge organization.

As a case study of how the DIKW hierarchy can shed light on problems in knowledge organization, I want to use it as background and starting point for reflecting 
on the opposite of knowledge. Looking at the way DIKW decomposes a sequence of levels surrounding knowledge invites us to wonder if an analogous sequence of stages surrounds ignorance, and where associated phenomena like credulity and misinformation fit. These concepts need to be understood in the context of knowledge organization. Besides psychological and sociological aspects, we would want to know how the opposite of knowledge coheres conceptually, whether it constitutes a domain, and how it is organized and positioned in knowledge organization systems.

Why would we want to know what the opposite of knowledge is? Ignorance, misinformation, stupidity, and so forth do have discourses about them and it would be useful to discover their underlying interrelations. They are also a part of culture. Popular arts such as film and literature, as well as traditional folklore, all engage with ignorance, stupidity, and error. Furthermore, a theory of the opposite of knowledge in bibliography tests the boundaries of our concepts about knowledge. An investigation toward such a theory asks, in effect, what, if anything, resides outside the universe of documentary knowledge, how would we describe it, how would be gain access to it, how should we organize it in libraries, and how, if at all, should it be identified to distinguish it from valid knowledge.

To identify the negative counterparts to the terms in the Data-InformationKnowledge-Wisdom hierarchy we might start by simply finding common antonyms for each term. This produces the following results:

$\begin{array}{ll}\text { Data } & \text { Absence or want of data; missing data } \\ \text { Information } & \text { Misinformation; disinformation; error } \\ \text { Knowledge } & \text { Ignorance } \\ \text { Wisdom } & \text { Folly; stupidity }\end{array}$

Notice there is no single term for the opposite of data. Nevertheless, the idea of a want of data or a gap in data does cohere as a comprehensible concept, and could be a topic of writing. Frické (2009), for one, argues that for data to be data they must be true, and that mistaken data are not data at all. This suggests that the notion of an opposite of data is a logical possibility.

For 'information' we find several different opposites. An error is a mistake made inadvertently or in ignorance, while misinformation is wrong information or a false account of intelligence received, and disinformation is the deliberate dissemination of false information with the intention of influencing the opinions and even policies of those receiving it. These concepts suggest a continuum from error to disinformation based on one's state of awareness, volition, and culpability.

Unlike the other terms in this schema, 'knowledge' has an obvious single opposite, namely 'ignorance.' But knowledge itself is highly slippery concept, since it is culturally and linguistically relative and can be made obsolete. Just as there are many kinds of knowledge, there may be many kinds of ignorance.

'Wisdom' yields two antonyms in the English language, 'stupidity' and 'folly'. Although the terms do not completely overlap in meaning, they do seem on initial examination to be interchangeable in some senses, except that 'stupidity' connotes lack of intelligence, or mental capacity, as well as lack (and indeed the inverse) of wisdom. Although most psychologists and other writers have long taken care to distinguish 
stupidity from mental disability, the actual meaning of stupidity is not sharply defined in relation to folly. Ackoff himself $(1989,5)$ took into account the critical role of intelligence in knowledge systems when he defined it as "the ability to acquire knowledge on one's own."

Emerging from the above analysis is a separation of error and folly, with folly being a more entrenched form of compounded errors, just as wisdom involves the synthesis or compounding of knowledge. But ultimately I reject my own hypothesis that the opposites of data, information, knowledge, and wisdom form a series mirroring DIKW. Errors can ensue even with the presence of accurate data or information, through misinterpretation or unsound reasoning, and misinformation and disinformation proceed not from a want of data but from distorting or incorrectly communicating information or knowledge, including information and knowledge that is correctly understood at the source. These hazards, and probably others, can intervene at different points in the development from data towards wisdom.

Nevertheless, the various phenomena I have identified as contrary to knowledge do seem to cohere as some kind of category. At this point I want to use the word nonknowledge, literally meaning "want of knowledge," and extend it to cover this entire spectrum from absence of data to stupidity and beyond. Given that knowledge is understood through DIKW to be connected in a system of interconnected and verbally identified phases representing different levels of complexity, synthesis, and refinement, there is a need for a concept that unites all the negative counterparts to these processes and phenomena. Just as DIKW does not only posit a hierarchy but explores the relations between data, information, knowledge, and wisdom, I would like to examine relations between phenomena on the negative side.

As might be expected, the literatures on error, stupidity, folly, misconceptions, and ignorance are disconnected. Some of these subjects appear to have undergone minor reawakened interest. At least three serious books on stupidity have appeared in English since the year 2000: The Encyclopaedia of Stupidity by Matthijs van Boxsel (2003), Stupidity by Avital Ronell (2002), and Why Smart People can be so Stupid, edited by Robert J. Sternberg (2002). As indicated in the title of the latter book, the recent literature distinguishes stupidity from low I.Q. This distinction was blurred in some writings on the subject up until the 1950s. Even so, the exact meaning of stupidity is sometimes unclear, since various authors think it is something outside the boundaries of discourse and inquiry. Boxsel, in his Encyclopaedia of Stupidity (2003, 29), says that "Stupidity is unfathomable; it can only be defined negatively, by contrast with another quality or as a deficit." This view, first expressed by the Austrian novelist Robert Musil (1990) in a 1937 lecture, sums up the paradox or riddle of conceptualizing stupidity. People point out what is stupid in others, but even when it is recognized in oneself, the stupidity of an action or phenomenon is only noticed in hindsight, and it does not seem to be a coherent quality in its own right. James F. Welles, author of the important but little-known and apparently self-published Understanding Stupidity (1986), suggests there is a taboo on examining stupidity, which he believes has shaped history far more than has knowledge or wisdom.

Despite or perhaps because of the sense of imponderability and indefinableness expressed about stupidity, it is clear that attention to it has increased in recent years. The analysis of stupidity is slowly coming into focus as an intellectually coherent and 
legitimate subject matter, even though it is still in its formative stage. Similarly, a new book called The Virtues of Ignorance, edited by Vitek and Jackson (2008), calls for a reappraisal of our culture's knowledge-based worldview inspired by the enlightenment and a shift to a worldview that enables us to admit our almost total ignorance as a species. Postmodern theory, which posits that knowledge and rationality are coercive and hegemonic practices, helps open up a space for such subversive analyses.

But while some of the recent literature on stupidity might have been sparked or flavored by postmodern epistemologies, Welles's book, Understanding Stupidity, which is not cited by any other author, does not fit this description. Welles, whose academic background is in zoology, is alone in examining stupidity in and of itself rather than from the perspective of any individual discipline. He defines stupidity in terms of maladaptive responses to change. In stupidity the response to changing conditions is either insufficient, due most likely to self-deception and the tendency to stick to known ways of thought behavior, or an overly drastic and radical response that is not informed by data. The failure to recognize change that requires response arises from the tendency to insulate oneself from information about changes, which could help one devise an appropriate adaptive response. This analysis in terms of assessing information and using it to make an appropriate response and the ability to detect errors fits neatly with Ackoff's (1989) view of knowledge as the means to control a situation for a desirable outcome. The difference between stupidity and ignorance, for Welles, lies in the adaptiveness or functionality of not heeding available information. In ignorance, unlike stupidity, a socially and psychologically adaptive mechanism is at work blocking the unwanted information from penetrating the cognitive system. Only in stupidity does the failure to absorb and process information work against one's best interest.

Smithson (1989), who focuses on ignorance, makes a similar point without mentioning stupidity by positing "irrelevance" as one of the two categories of ignorance, along with error. Irrelevance means deciding that something is irrelevant based on untopicality, undecidability, or taboo. Disregarding information due to untopicality would be in Welles's terms an adaptive filtering mechanism, whereas the shunning of information as taboo may well be maladaptive, in which case it would lead to stupidity.

Folly has been mentioned along with stupidity as an antonym of wisdom. A quasireligious concept of the fool, portrayed as court-jesters and merry-makers, came to the fore in medieval Europe and was canonized as a theme in literature first in Sebastian Brant's 1494 Ship of Fools by Sebastian Brant and then in 1511 by Desiderius Erasmus in The Praise of Folly. Despite the unserious depiction of fools, folly was identified as moral failure. This attribute helps us define it as a species of nonknowledge, since Ackoff specifically mentions morality as a key component in the development of knowledge toward a condition of wisdom.

The word 'folly' also has the modern connotations of fallacies and misunderstandings resulting in devastation and calamity. This sense of folly as "policy contrary to self-interest" is expounded upon by Barbara Tuchman in The March of Folly: from Troy to Vietnam (1984). A policy or decision may seem correct or sensible when it is made, and it only becomes apparent later, after the damage is done, that the decision or policy was misguided. Folly in this sense follows from errors. In Deadly 
Decisions, Christopher Burns (2008) looks at the background of the sinking of the Titanic, the explosion of the space shuttle Challenger, and other disasters, finding that in all cases warnings were ignored, system safeguards designed to alert operators about a crisis blocked or disguised real data, communication systems broke down, and blame and even error were denied and covered up by all parties. The literature on folly in this sense is cataloged with the Library of Congress Subject Heading 'Error' rather than 'Folly', but it can be seen that folly proceeds from error and exacerbates it. The titles of other recent books also reveal this concept of folly, even though they are not assigned 'Folly' as a subject heading: Profiles in Folly: History's Worst Decisions and Why they Went Wrong by Alan Axelrod (2008) and How to Lose a Battle: Foolish Plans and Great Military Blunders by Bill Fawcett (2006). The study of error or folly in this sense would apply to ongoing crises such as global warming and the subprime mortgage debacle.

A related species of nonknowledge is popular misconceptions arising from credulity. A classic in the field is Charles Mackay's Extraordinary Popular Delusions and the Madness of Crowds, first published in 1841 and widely reprinted. The subject has been taken up most recently by Damian Thompson in Counterknowledge (2008), which covers creation science, alternative medicine, get rich quick schemes, alternative histories as evidenced in Afro-centric textbooks, and web sites promulgating conspiracy theories about the September 11 terrorist attacks. In many instances, counterknowledge begins with errors, but there is often awareness of untruthfulness if not outright deceptive intent in the dissemination of misinformation. Thompson identifies an entire "counterknowledge industry," which includes authors and publishers, who value profits over other concerns. Nor can booksellers be counted on to distinguish science from pseudoscience, or history from pseudo-history. The products of the counterknowledge industry produces make their way into libraries, where materials are selected according to how they meet the community's needs. As library materials, they must be cataloged according to their subject. Now counterknowledge can serve useful purposes in a library collection, but it can also spawn further misinformation and error. Therefore, the treatment of counterknowledge, or nonknowledge, in libraries and information services raises important problems and responsibilities (see Swan \& Peattie 1989).

Indeed, it is important to distinguish between the various areas of nonknowledge as a subject treated by writers from various disciplines and angles (history, psychology, etc.) and nonknowledge as content. The clearest examples of nonknowledge as the content rather than subject matter of documents are fraud (including forgery) and propaganda. Fraud is a deliberate as opposed to inadvertent misrepresentation resulting in false conclusions conveyed by fabricating and distorting evidence. A claim of encountering the Loch Ness monster may honestly represent a person's subjective experience or it may be a fantasy or tall tale, but creating or planting false evidence to back up such a claim is fraud. Propaganda is the technique of influencing human action by the manipulation of representations to evoke a certain response. Recalling Ackoff's point about knowledge being for control, it may be noted here that propaganda is created with the intent of controlling the reader either in beliefs or emotions, so that the consumer of propaganda is the one being controlled! Both fraud and propaganda involve deliberate deception by disguising falsehoods as facts with the 
purpose of tricking readers. As such, neither fraud nor propaganda is ever selfidentified as such. As with errors, stupidity, and folly, it remains for the information consumer to discover them.

To review, we have identified several categories of nonknowledge standing as counterpoints to data, information, knowledge, and wisdom. Although we can conceive of an antithesis to each term in the DIKW hierarchy, the opposites of data, information, knowledge, and wisdom do not form a pyramid. It is not the case that the opposite of data leads to the opposite of information, etc. But there is no real reason to expect such a sequence. The purpose of the exercise is to develop a comprehensive concept of nonknowledge that can then be broken down into phases or facets that interconnect. Data, information, knowledge, and wisdom provide terms that help us generate a classification of nonknowledge. We can also see different levels of intensity and consequentiality in nonknowledge. Clearly, folly is the aggravated outcome of certain kinds of errors. Popular misconceptions also proceed from errors in thought along with gullibility and deception. Meanwhile, stupidity has been identified as a maladaptive variety of ignorance.

To conclude, the hierarchical way of thinking about the relations between data, information, knowledge, and wisdom spawned by Ackoff's DIKW hierarchy can serve as an intriguing framework for considering the opposite of knowledge as a spectrum, and this lets us circumscribe a domain we can call nonknowledge, which posits opposites of each of the terms in the DIKW hierarchy. Investigation into the areas of stupidity, folly, errors, misinformation, and data gaps finds important connections between these areas, though not a perfect mirror of DIKW. Then again, it is wrong to assume that the DIKW model accurately reflects the stages of the development of knowledge, and the hierarchy itself seems due for a fresh reappraisal if not necessarily banishment from the canon of information science, as Martin Frické (2009) advocates. Even though nonknowledge cannot be decomposed into a strictly ranked order of levels it is still possible for us to discern a hierarchy from simple to complex, entrenched, and aggravated modes of nonknowledge. Nonknowledge is part of the world we live in, and it presents special challenges in knowledge organization, particularly in differentiating nonknowledge as a topic and as a form. Finally, by revealing these interconnections, we see the potential for nonknowledge studies to further examine problems within the compass of nonknowledge.

\section{References}

Ackoff, R. L. (1989). From data to wisdom. Journal of Applied Systems Analysis 15: 3-9.

Boxsel, Matthijs van (2003). The encylopaedia of stupidity, trans. Arnold and Erica Pomerans. London: Reaktion.

Buckland, Michael. (1991). Information and information systems. New York: Greenwood Press.

Burns, Christopher (2008). Deadly decisions: How false Knowledge sank the Titanic, blew up the shuttle and led America into war. Amherst, NY: Prometheus Books.

Frické, Martin. (2009). The knowledge pyramid: A critique of the DIKW hierarchy. Journal of Information Science 35: 131-142. 
Machlup, Fritz (1980). Knowledge and knowledge production. Princeton, NJ: Princeton University Press.

Musil, Robert (1990). On stupidity. In Precision and soul: Essays and addresses, ed. and trans. Burton Pike \& David S. Luft. Chicago: University of Chicago Press. Pp. 268-286.

Rowley, Jennifer (2007). The wisdom hierarchy: Representations of the DIKW hierarchy. Journal of Information Science 33: 163-180.

Sharma, Nikhil (2008). The origin of the "data information knowledge wisdom" hierarchy. [http://www-personal.si.umich.edu/ nsharma/dikw_origin.htm]. Accessed May 15, 2009.

Smithson, Michael (1989). Ignorance and uncertainty: Emerging paradigms. New York: Springer-Verlag.

Soergel, Dagobert (1985). Organizing information: Principles of data base and retrieval systems. Orlando, FL: Academic Press.

Swan, John \& Peattie, Noel (1989). The freedom to lie: A debate about democracy. Jefferson, NC: McFarland \& Company.

Thompson, Damian (2008). Counterknowledge: How we surrendered to conspiracy theories, quack medicine, bogus science, and fake history. New York: W. W. Norton \& Co.

Tuchman, Barbara (1984). The march of folly: From Troy to Vietnam. New York: Alfred A. Knopf.

Vitek, Bill \& Jackson, Wes ed. (2008). The virtues of ignorance: Complexity, sustainability, and the limits of knowledge. Lexington: University Press of Kentucky.

Welles, James F. (1986). Understanding stupidity: An analysis of the premaladaptive beliefs and behavior of institutions and organizations. Orient, N.Y.: Mount Pleasant Press. Also [www.stupidity.net/story2/index2.htm]. Accessed May 21, 2009.

Zins, Chaim (2007). Conceptual approaches for defining data, information, and knowledge. Journal of the American Society for Information Science and Technology 58: 479-493. 